\title{
Correction of the Chlorophyll $a$ Fluorescence Quenching in the Sea Upper Mixed Layer: Development of the Algorithm
}

\author{
N. A. Moiseeva ${ }^{1, *}$, T. Ya. Churilova ${ }^{1}$, T. V. Efimova ${ }^{1}$, D. N. Matorin ${ }^{2}$ \\ ${ }^{1}$ A.O. Kovalevsky Institute of Biology of the Southern Seas, Russian Academy of Sciences, \\ Sevastopol, Russian Federation \\ ${ }^{2}$ Lomonosov Moscow State University, Moscow, Russian Federation \\ *nataliya-moiseeva@yandex.ru
}

Purpose. Data from the immersion fluorescence sensors of the CTD complex and BioArgo floats are widely used for studying spatial and temporal variability of the chlorophyll a concentration on large scales. In these devices the fluorescence sensors are not equipped with a dark chamber; as a result, a part of the reaction centers of photosystem 2 is closed due to the sunlight effect. It is manifested in decrease of the measured fluorescence intensity in the upper mixed layer due to fluorescence quenching, while the chlorophyll a concentration can remain unchanged. The purpose of the work is to develop the algorithm for correcting the fluorescence quenching.

Methods and Results. It is shown that photosynthetically available radiation decreases with depth within the upper mixed layer by almost an order, and the chlorophyll a fluorescence measured by the immersion sensor (without a dark chamber), increases with depth in this layer. Relationship between light intensity and share of open reaction centers of photosystem 2 in cell of microalgae was revealed. The relationship is described by the exponential function. The share of open centers effects on the degree of fluorescence intensity decreasing and therefore on fluorescence quenching induced by light.

Conclusions. The universal algorithm for correcting fluorescence quenching in the upper mixed layer is proposed. Due to its correction, almost uniform fluorescence distribution is obtained in the upper mixed layer which is in a good consistence with the results of chlorophyll a concentration measurements in situ.

Keywords: fluorescence, photochemical and non-photochemical quenching, reaction centers, photosystem 2, chlorophyll a concentration, phytoplankton, BioArgo floats.

Acknowledgments: the research was carried out according to the themes "Study of Spatial-Temporal Organization of Aquatic and Land Ecosystems Aimed at Development of Operational Monitoring System based on the Remote Sensing Data and GIS Technologies" No. AAAA-A19-119061190081-9 and "Comprehensive Studies of the Current State of the Ecosystem of the Atlantic Sector of the Antarctic" (No. AAAA-A19-119100290162-0) as well as at partial RFBR support, grants No. 18-45-920070.

For citation: Moiseeva, N.A., Churilova, T.Ya., Efimova, T.V. and Matorin, D.N., 2020. Correction of the Chlorophyll a Fluorescence Quenching in the Sea Upper Mixed Layer: Development of the Algorithm. Physical Oceanography, [e-journal] 27(1), pp. 60-68. doi:10.22449/1573-160X-2020-1-60-68

DOI: 10.22449/1573-160X-2020-1-60-68

(C) N.A. Moiseeva, T.Ya. Churilova, T.V. Efimova, D.N. Matorin, 2020

(C) Physical Oceanography, 2020

\section{Introduction}

Concentration of chlorophyll $a\left(C_{a}\right)$, being the main photosynthetically active pigment, is used to calculate primary production (PP) and assess trophic status of the water area. Standard spectrophotometric method of $C_{a}$ determination $^{1}$ is painstaking, requires special equipment and is carried out only in laboratory conditions. Currently, as an alternative approach to $C_{a}$ estimation, a fluorimetric

${ }^{1}$ Gosstandart, 1999. State Standart 17.1.4.02-90. Method of Spectrophometric Determination of Chlorophyll a. Moscow: IPK Izdatel'stvo Standartov, 14 p. (in Russian). 
method for $C_{a}$ determination based on the relationship between $C_{a}$ and fluorescence has become widespread $[1,2]$. The accuracy of the fluorimetric method for $C_{a}$ calculating is determined by the correctness of this ratio assessment, which is especially important for mesotrophic waters [3].

In natural water bodies, the fluorescence intensity profile $(F)$ is measured by a special sensor mounted on the CTD hydrological complex. For long-term observations with high spatial resolution, various drifting floats are used, including floats of the Biogeochemical-Argo project (BGC-Argo). Modern models make it possible to measure vertical profiles of hydrophysical/hydrochemical parameters, including the chlorophyll $a$ fluorescence. BGC-Argo floats are widely used for research in various parts of the World Ocean, including the Black Sea (http://biogeochemical-argo.org/).

In vivo the chlorophyll $a$ fluorescence intensity of $\left(F, \mu \mathrm{E} \cdot \mathrm{m}^{-3} \cdot \mathrm{s}^{-1}\right)$ is known [4] to depend on the light conditions of the environment (photosynthetically available radiation $\left.(\mathrm{PAR}), \mu \mathrm{E} \cdot \mathrm{m}^{-2} \cdot \mathrm{s}^{-1}\right)$, the chlorophyll $a$ concentration $\left(C_{a}, \mathrm{mg} \cdot \mathrm{m}^{-3}\right)$ and the physiological characteristics of phytoplankton $\left(a_{\mathrm{ph}}^{*}(\lambda), \varphi_{\mathrm{F}}\right)$ :

$$
F=\operatorname{PAR} \cdot C_{a} \cdot \bar{a}_{\mathrm{ph}}^{*} \cdot Q_{a}^{*} \cdot \varphi_{\mathrm{F}}
$$

where $\bar{a}_{\mathrm{ph}}{ }^{*}-$ spectrally average value of chlorophyll a specific light absorption coefficient by phytoplankton pigments $a_{\mathrm{ph}}^{*}(\lambda), \mathrm{m}^{2} \cdot \mathrm{mg}^{-1} ; \varphi_{\mathrm{F}}-$ quantum fluorescence yield, mole of emitted photons/mole of absorbed photons; $Q_{a}^{*}-$ dimensionless fluorescence intracellular reabsorption coefficient, dimensionless.

Taking into account the above dependence (1) in the upper mixed layer with a uniform distribution of $C_{a}$ and $a_{\mathrm{ph}}$ the fluorescence intensity should be constant within the upper mixed layer limits. It should be noted the design feature of the sensors used with the CTD complex and in the BGC-Argo floats: they do not have a dark champer. In such sensors, $F$ measurement in vivo occurs without preliminary dark adaptation of phytoplankton necessary for opening all the reaction centers (RC) of photosystem 2 (PS 2), which is associated with the processes of $\mathrm{H}_{2} \mathrm{O}$ decomposition and $\mathrm{O}_{2}$ release. During daylight hours, as a result of the sunlight action, the RC PS 2 part goes into an inactive state and non-photochemical quenching of fluorescence develops, leading to an underestimation of the F values in the subsurface sea layer [5]. Non-photochemical quenching of fluorescence is associated with a number of photoinduced processes, such as the electrochemical proton gradient formation on thylakoid membranes, quenching of fluorescence by carotenoids (zeaxanthin), and, finally, photo destruction of RC PS 2 [6].

The present paper is aimed to create an algorithm that will allow correction of the chlorophyll $a$ fluorescence quenching, measured at sea using immersion sensors. Testing of the developed algorithm is carried out on the example of the Black Sea. 


\section{Methods}

Works were carried out on October 24 - 28, 2017, when seasonal stratification of waters was observed in the deep Black Sea. An SBE 911plus probe (Sea-Bird Electronics) with sensors of temperature, salinity, density and fluorescence of chlorophyll $a(F)$ was used as a probe complex.

The light conditions for the phytoplankton existence at different depths throughout the euphotic layer were determined using the Bouguer - Lambert equation of light attenuation [7]:

$$
P A R_{Z}=P A R_{0} \cdot e^{-K_{\mathrm{d}} \cdot z}
$$

where $P A R_{Z}-\mathrm{PAR}$, penetration to $z$-depth; $P A R_{0}-\mathrm{PAR}$, falling to the sea surface; $K_{\mathrm{d}}$ - diffuse attenuation coefficient, estimated based on depth of Secchi disk visibility $\left(Z_{\mathrm{S}}\right)[8]$ :

$$
K_{\mathrm{d}}=1,08 Z_{\mathrm{S}}^{-0,79}
$$

The euphotic zone $\left(Z_{\mathrm{eu}}\right)$ was taken equal to the penetration depth of $1 \%$ of the $P A R_{0}$ value. $Z_{\mathrm{eu}}$ was determined according to the formula [8]

$$
Z_{\mathrm{eu}}=4,6 / K_{\mathrm{d}}
$$

where 4.6 corresponds to the optical depth $\left(K_{\mathrm{d}} \cdot z\right)$, which $1 \% P A R_{0}$ penetrates to.

$E_{0}$ was estimated according to the formula [9, p. 5] taking into account cloudiness degree in the day of measurements. For the upper mixed layer the mean value of light intensity for layer from the sea surface to the bottom $\left(P A R_{U M L}\right)$ was calculated as described in [10, p. 1266]:

$$
\overline{P A R}_{U M L}=\overline{P A R}_{0} \frac{\left[1-e^{-4,6 \frac{Z_{U M L}}{Z_{\mathrm{eu}}}}\right]}{4,6 \frac{Z_{U M L}}{Z_{\mathrm{eu}}}} .
$$

The experiments in the research vessel laboratory to evaluate the parameters of the variable fluorescence of phytoplankton, adapted to different light conditions of existence in the upper mixed layer, were also carried out. The fluorescence intensity was measured with a MEGA-25 laboratory fluorometer with high sensitivity, developed at the Department of Biophysics, Faculty of Biology, Moscow State University [11]. This instrument supports to determine the chlorophyll $a$ fluorescence values with high sensitivity on natural phytoplankton: $F_{0}$ (constant fluorescence with opened RC PS 2), $F_{\mathrm{m}}$ (maximum fluorescence with closed RC PS 2), $F_{\mathrm{V}} / F_{\mathrm{m}}$ (quantum yield of light energy use with opened RC PS 2) after dark adaptation and also $F_{\mathrm{t}}$ (a quasistationary level of fluorescence in an object adapted to light) and $F_{\mathrm{m}}^{\prime}$ (maximum fluorescence after continuous irradiance) in 
constant light - and calculate the photochemical and non-photochemical quenching of fluorescence induced by light in an experiment.

$F_{\mathrm{m}}$ and $F_{\mathrm{m}}^{\prime}$ were determined under illumination with a saturating flash (duration $0.8 \mathrm{~s}$, intensity $\left.5000 \mu \mathrm{E} \cdot \mathrm{m}^{-2} \cdot \mathrm{s}^{-1}\right)$. The fluorescence intensity decrease due to the use of light energy in photosynthetic reactions is called photochemical quenching of fluorescence caused by acting light, and characterizes the activity of RC PS 2:

$$
q_{\mathrm{P}}=\frac{F_{\mathrm{m}}^{\prime}-F_{\mathrm{t}}}{F_{\mathrm{m}}^{\prime}-F_{0}^{\prime}},
$$

where $F_{0}^{\prime}$ - continuous fluorescence after light adaptation of phytoplankton.

The fluorescence signal decrease as a result of thermal dissipation of the excitation energy is called non-photochemical quenching. These parameters allow estimation of the ratio of open and closed photosynthesis centers in the light. The measuring technique of the reduced parameters and their physical meaning are described in detail in $[6,12]$.

\section{Results}

In the middle of daylight hours in the upper mixed layer, the $F$ values measured near the sea surface were less than the values recorded in the lower part of the upper mixed layer (Fig. 1, green line).
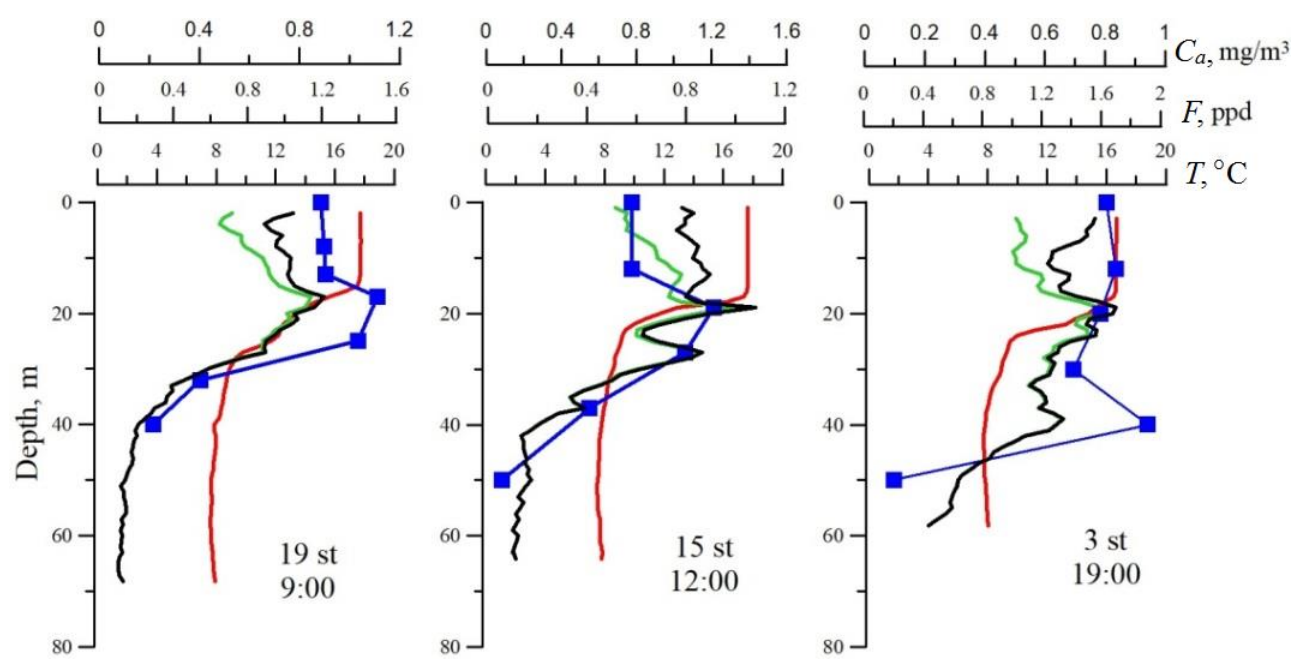

F i g. 1. Profiles of vertical distribution of temperature $T$ (red line), fluorescence intensity $F$ measured by the immersion sensor of SBE 911 plus probe (green line); profile $F$ reconstructed with account of light intensity (black line); chlorophyll $a$ concentration $C_{a}$ (blue squares) at the individual stations in different periods of a day, October 2017 
In the considered period $P A R_{0}$ was $\sim 20 \mathrm{E} \cdot \mathrm{m}^{-2} \cdot$ day $^{-1}$ (at 4 stations) and $\sim 15 \mathrm{E} \cdot \mathrm{m}^{-2} \cdot \mathrm{day}^{-1}$ (at 6 stations), which, taking into account the 9.6-hour daylight hours, was 580 and $450 \mu \mathrm{E} \cdot \mathrm{m}^{-2} \cdot \mathrm{s}^{-1}$, respectively. The homogeneous distribution in the upper mixed layer suggests that the phytoplankton in this layer mixes quite quickly and does not have time to adapt to conditions at a specific depth of the upper mixed layer. In this case, the physiological characteristics of phytoplankton $\left(a_{\mathrm{ph}}^{*}(\lambda)\right.$, $\varphi_{\mathrm{F}}$ ) reflect its adaptation to $P A R_{U M L} . P A R_{U M L}$ varied between stations from 140 to $290 \mu \mathrm{E} \cdot \mathrm{m}^{-2} \cdot \mathrm{s}^{-1}$. About $8 \%\left(\sim 1.4 \mu \mathrm{E} \cdot \mathrm{m}^{-2} \cdot \mathrm{s}^{-1}\right)$ of $P A R_{0}$ penetrated the lower boundary of the upper mixed layer $(\sim 18 \mathrm{~m})$, which indicates a high gradient of the PAR in the layer. Taking into account the homogeneity of the upper mixed layer in temperature, values $C_{a}$ and $a_{\mathrm{ph}}(455)$ [13], the $F$ decrease (according to the data of the immersion probe) within the upper mixed layer limits is due to a change in the proportion of open RC PS $2\left(d_{o p}\right)$ algal cells under the PAR influence and corresponds to $q_{\mathrm{P}}$. The $d_{o p}$ value decreases with the increase of PAR level in the phytoplankton habitat. Under the constant light $d_{o p}$ can be determined by the formula (3) [14, p. 724], where $F_{\mathrm{t}}$ is the quasistationary level of phytoplankton fluorescence adapted to light corresponding to the natural conditions of existence.

According to the measurement data at the separate upper mixed layer depth the relation between $d_{o p}$ and PAR was obtained (Fig. 2), which is described by an exponential dependence (when PAR $=0$ all the RCs are open, correspondingly $\left.d_{o p}=1\right)$ :

$$
d_{o p}=e^{-0,0019 \cdot P A R} .
$$

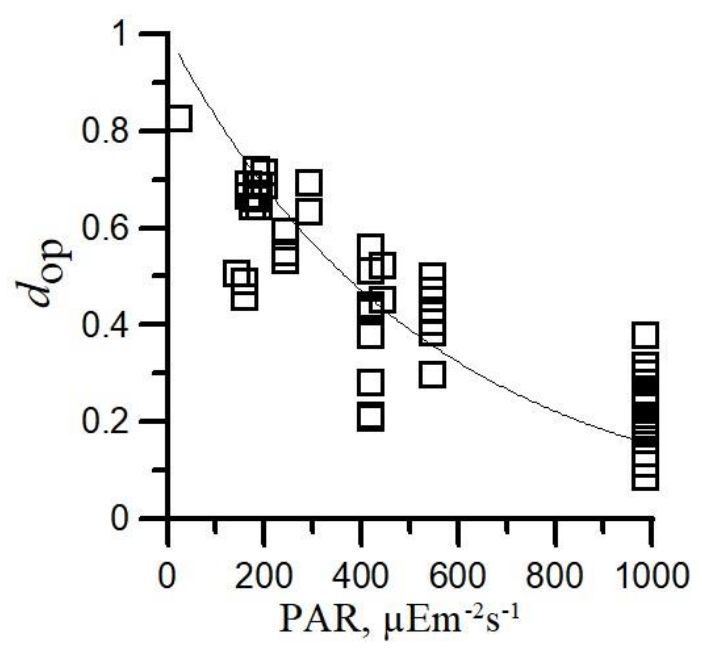

F i g. 2. Dependence of the value of a portion of the open reaction centers (photosystem 2) ( $\left.d_{\text {op }}\right)$ upon light intensity (photosynthetically available radiation) in the Black Sea upper mixed layer in October, 2017 
Based on the data on $\mathrm{PAR}_{0}$ and $K_{\mathrm{d}}$ using the equations (2) and (4) $d_{o p}$ were calculated for the upper mixed layer with high resolution in depth $(1 \mathrm{~m})$ :

$$
d_{o p}(z)=e^{-0,0019 \cdot\left(P A R_{0} \cdot e^{-K_{d} \cdot z}\right)}
$$

Due to the lack of dark adaptation of phytoplankton when measuring $\mathrm{F}$ in vivo, the obtained data corresponds to $F_{\mathrm{t}}$ that reflects the intensity of phytoplankton fluorescence adapted to light (natural lighting conditions). Under these conditions, phytoplankton cells have open and closed reaction centers of photosynthesis. The proportion of closed RCs $\left(d_{\text {closed }}\right)$, that is, RCs that are not involved in photosynthesis and have a high level of non-photochemical quenching of fluorescence, was determined by the following formula

$$
d_{\text {closed }}=1-d_{o p}
$$

The potential $F$ of the closed RCs, which is not registered by immersion sensors (without a dark chamber) used in combination with CTD and in BGC-Argo floats, it is determined by the expression

$$
F_{\text {closed }}=F_{t} \cdot d_{\text {closed }}
$$

To level the light-induced decrease in $F$ in the upper mixed layer and restore the profile of real $F\left(F_{\text {real }}\right)$, it is necessary to take into account $F_{\text {closed: }}$ :

$$
\begin{gathered}
F_{\text {real }}=F_{t}+\left(F_{t}\left(1-e^{-0,0019\left(P A R_{0} \cdot e^{-K_{d} \cdot z}\right)}\right)\right), \\
F_{\text {real }}=F_{t}\left(2-e^{-0,0019 \cdot P A R_{0} \cdot e^{-K_{d} \cdot z}}\right) .
\end{gathered}
$$

The fluorescence profiles recalculated according to equation (6) and probe data are shown in Fig. 1.

As a result of the correction of fluorescence quenching, it was obtained (Fig. 1), that $F_{\text {real }}$ exceeds the measured $F$ within the entire upper mixed layer. The greatest differences between $F_{\text {real }}$ and $F$ were obtained in the surface layer (37-51\%). Thus, the use of the algorithm developed by the authors led to an increase in fluorescence in the surface layer by $\sim 1.4-1.5$ times. The correctness of the change depends on the accuracy of the assessment of light conditions. Due to the fact that the average exposure level was applied for daylight hours, the highest accuracy of restoration for daytime soundings was obtained. 


\section{Discussion}

When working with chlorophyll $a$ fluorescence measurement data recorded using an immersion probe not equipped with a camera for dark adaptation of phytoplankton, the light effect in the upper mixed layer on the fraction of inactive photosynthesis reaction centers should be taken into account, which determines the non-photochemical quenching of fluorescence (equation (1)). Earlier, for BGCArgo floats, to level out the illumination effect on the value of $F$, it was proposed to use the $F$ data obtained at nighttime [15]. However, this approach (excluding daytime measurements $F$ ) limits the amount of data $F$, therefore, limits biological research based on measurements using floats. It should be noted that the measurement of the transparency of waters and PARs, which are important environmental factors determining the primary production characteristics of phytoplankton, can only be carried out during daylight hours.

In the present study, based on the obtained dependence of the fraction of closed RC PS 2 on PAR, an algorithm for correcting the chlorophyll $a$ fluorescence quenching in the upper mixed layer is developed. Using this algorithm allows restoring the real profile of chlorophyll $a$ concentration. In fact, using the algorithm, the fluorescence values for the case when all RC PS 2 are open and active and, therefore, quenching of $F$ is absent (equal to 0 ), are obtained. The dependence of the ratio of open and closed centers on the PAR (equation (5)) is of a general nature; therefore, an algorithm based on this dependence can be used to restore the vertical fluorescence profile, and, consequently, the chlorophyll $a$ concentration in different water areas. The exponential dependence coefficient (equation (5)) was obtained for the PAR value averaged over daylight hours. In order to refine the algorithm in the future, it is planned to study how the value of this coefficient changes during daylight hours.

\section{Conclusions}

The universal algorithm for correcting fluorescence quenching in the upper mixed layer is proposed. Due to its correction, almost uniform fluorescence distribution is obtained in the upper mixed layer which is in a good agreement with the results of chlorophyll a concentration measurements in situ.

\section{REFERENCES}

1. Falkowski, P.G. and Raven, J.A., 2007. Aquatic Photosynthesis. Princeton: Princeton University Press, 488 p.

2. Suggett, D.J., Prášil, O. and Borowitzka, M.A., 2010. Chlorophyll a Fluorescence in Aquatic Sciences: Methods and Applications. Dordrecht: Springer, 323 p. doi:10.1007/978-90-481-9268-7

3. Sorokin, Yu.I., 1982. [Black Sea: Nature, Resources]. Moscow: Science, 217 p. (in Russian).

4. Babin, M., 2008. Phytoplankton Fluorescence: Theory, Current Literature and in situ Measurement. In: M. Babin, C.S. Roesler, J.J. Cullen, eds., 2008. Real-Time Coastal 
Observing Systems for Marine Ecosystem Dynamics and Harmful Algal Blooms: Theory, Instrumentation and Modelling. Paris: UNESCO Publishing, pp. 237-280.

5. Pogosyan, S.I. and Matorin, D.N., 2005. Variability in the State of the Photosynthetic System of the Black Sea Phytoplankton. Oceanology, 45(suppl. 1), pp. S139-S148. Available at: http://www.library.biophys.msu.ru/matorin/3385.pdf [Accessed: 10 November 2019].

6. Schreiber, U., Bilger, W. and Neubauer, C., 1995. Chlorophyll Fluorescence as a Nonintrusive Indicator for Rapid Assessment of in vivo Photosynthesis. In: E.D. Schulze and M.M. Caldwell, eds., 1995. Ecophysiology of Photosynthesi. Berlin: Springer, pp. 49-70. https://doi.org/10.1007/978-3-642-79354-7_3

7. Kirk, J.T.O., 2011. Light and Photosynthesis in Aquatic Ecosystems. Cambridge: Cambridge University Press, 649 p.

8. Vedernikov, V.I., 1989. [Primary Production and Chlorophyll in the Black Sea in the Summer-Fall Season]. In: M.E. Vinogradov and M.V. Flint, eds., 1989. [The Structure and Production Characteristics of Plankton Communities in the Black Sea]. Moscow: Nauka, pp. 65-83 (in Russian).

9. Suslin, V.V., Korolev, S.N., Kucheryaviy, A.A., Churilova, T.Ya. and Krivenko, O.V., 2015. Photosynthetically Available Radiation on Surface of the Black Sea Based on Ocean ColorData. In: SPIE, 1990. Proceedings SPIE. Vol. 9680: 21st International Symposium Atmospheric and Ocean Optics: Atmospheric Physics. 96800T. https://doi.org/10.1117/12.2203660

10. Babin, M., Morel, A., Claustre, H., Bricaud, A., Kolber, Z., Falkowski, P.G., 1996. Nitrogen- and Irradiance-Dependent Variations of the Maximum Quantum Yield of Carbon Fixation in Eutrophic, Mesotrophic and Oligotrophic Marine Systems. DeepSea Research Part I: Oceanographic Research Papers, 43(8), pp. 1241-1272. https://doi.org/10.1016/0967-0637(96)00058-1

11. Pogosyan, S.I., Galchuk, S.V., Kazimirko, Y.V., Konyukhov, I.V. and Rubin, A.B., 2009. Application of Fluorimeter "Mega-25" to Estimate the Quantity of Phytoplankton and Assess Its Photosynthetic Status. Water: Chemistry and Ecology, (6), pp. 34-40 (in Russian).

12. Ostrowska, M., Majchrowski, R., Matorin, D. N. and Wozniak, B., 2000. Variability of the Specific Fluorescence of Chlorophyll in the Ocean. Part 1. Theory of Classical in situ Chlorophyll Fluorometry. Oceanologia, 42(2), pp. 203-219. Available at: https://www.iopan.pl/oceanologia/Art5.pdf [Accessed: 10 November 2019].

13. Moiseeva, N.A., Churilova, T.Ya., Efimova, T.V., Krivenko, O.V. and Matorin, D.N., 2019. Fluorescence of Chlorophyll a during Seasonal Water Stratification in the Black Sea. Physical Oceanography, 26(5), pp. 425-437. doi:10.22449/1573-160X-2019-5425-437

14. Falkowski, P. and Kiefer, D.A., 1985. Chlorophyll a Fluorescence in Phytoplankton: Relationship to Photosynthesis and Biomass. Journal of Plankton Research, 7(5), pp. 715-731. https://doi.org/10.1093/plankt/7.5.715

15. Wojtasiewicz, B., Hardman-Mountford, N.J., Antoine, D., Dufois, F., Slawinski, D. and Trull, T.W., 2018. Use of Bio-Optical Profiling Float Data in Validation of Ocean Colour Satellite Products in a Remote Ocean Region. Remote Sensing of Environment, 209, pp. 275-290. https://doi.org/10.1016/j.rse.2018.02.057 
About the authors:

Nataliya A. Moiseeva, Junior Research Associate, Geomatics Research Center, A.O. Kovalevsky Institute of Biology of the Southern Seas, Russian Academy of Sciences (2 Nakhimov Sq., Sevastopol, 299011, Russian Federation), ORCID ID: 0000-0003-1356-7981, Scopus Author ID: 57194431032, Author ID: 959717 SPIN-код: 8946-3315, nataliya-moiseeva@ yandex.ru

Tatiana Ya. Churilova, Leading Research Associate, Head of Geomatics Research Center, A.O. Kovalevsky Institute of Biology of the Southern Seas, Russian Academy of Sciences (2 Nakhimov Sq., Sevastopol, 299011, Russian Federation), Ph. D. (Biol.), ORCID ID: 0000-0002-0045-7284, Scopus Author ID: 6603622802, ResearcherID: 0-8437-2016, Author ID: 888565 SPIN-код: 2238-9533, tanya.churilova@gmail.com

Tatiana V. Efimova, Junior Research Associate, Geomatics Research Center, A.O. Kovalevsky Institute of Biology of the Southern Seas, Russian Academy of Sciences (2 Nakhimov Sq., Sevastopol, 299011, Russian Federation), ORCID ID: 0000-0003-3908-4160, Scopus Author ID: 57194423783, Author ID: 766926 SPIN-код: 1668-0742, tatyana-iefimova@ yandex.ru

Dmitiy N. Matorin, Leading Research Associate, Lomonosov Moscow State University (1 Leninskie Gory, Moscow, 119991, Russian Federation), Dr. Sci. (Biol.), Professor, ResearcherID: S-5443-2016, Scopus Author ID: 6701647993, matorin@biophys.msu.ru

Contribution of the co-authors:

Nataliia A. Moiseeva - preparation of the article text, collection of materials, data processing and analysis of the results

Tatiana Ya. Churilova - the problem statement, preparation of the article text

Tatiana V. Efimova - collection of materials, data processing, preparation of graphic materials

Dmitriy N. Matorin - preparation of the article text, consultations on the topic of the article

All the authors have read and approved the final manuscript.

The authors declare that they have no conflict of interest. 